Draškovoć, B., Berjan, S., Milić, V., Govedarica, B., Radosavac, A. (2021): Structure of agricultural land losses in Bosnia and Herzegovina. Agriculture and Forestry, 67 (1): 91-101

DOI: 10.17707/AgricultForest.67.1.08

\begin{abstract}
Branislav DRAŠKOVIĆ ${ }^{\prime}$, Siniša BERJAN, Vesna MILIĆ, Branka GOVEDARICA, Adriana RADOSAVAC ${ }^{2}$
\end{abstract}

\title{
STRUCTURE OF AGRICULTURAL LAND LOSSES IN BOSNIA AND HERZEGOVINA
}

\section{SUMMARY}

As the world's population grows, so does the pressure on agricultural land. Consequently, there is less and less agricultural land. Bosnia and Herzegovina is one of the countries whose population is decreasing from year to year, partly owing to negative natural increase and partly owing to the migrations of young people to developed western countries. However, despite the depopulation trend, there has been a significant decline in agricultural land in the first two decades of the twenty-first century. The reasons should be sought in various socio-economic processes that crucially affect spatial development. In order to understand the changes that are happening in the field, the paper analyzes the structure of agricultural land losses in $\mathrm{B} \& \mathrm{H}$ based on the database of the European project CORINE Land Cover. In relation to the five main land cover categories (artificial surfaces, agricultural areas, forests and semi-natural areas, wetlands and water bodies), the data show that in the period from 2000 to 2018 artificial areas increased spatial coverage, forests and semi-natural areas as well, while agricultural land decreased.

The aim of the research is to identify the spatially largest changes of agricultural land subclasses into other types of land cover, in order to determine the causes and areas with the most intense pressure. This is essential given the fact that agricultural land is becoming an increasingly important natural resource over time. Based on the recent demographic and socio-economic trends, it is to be expected that the trend of decreasing agricultural land will continue in the future, but with a reduced intensity.

Key words: agricultural land, losses, B\&H, CLC, CHA, database.

\footnotetext{
${ }^{1}$ Branislav Drašković (corresponding author: branislav.draskovic@pof.ues.rs.ba), Siniša Berjan, Vesna Milić, Branka Govedarica, University of East Sarajevo, Faculty of Agriculture, Vuka Karadžića 30, 71126 East Sarajevo, BOSNIA AND HERZEGOVINA.

${ }^{2}$ Adriana Radosavac, Faculty of Applied Management, Economics and Finance, University Business Academy in Novi Sad, Jevrejska 24, Belgrade, SERBIA.

Notes: The authors declare that they have no conflicts of interest. Authorship Form signed online. 


\section{INTRODUCTION}

Bosnia and Herzegovina (B\&H) is a country in the Western Balkans, with an area of $51209 \mathrm{~km}^{2}$. The Dayton Peace Agreement from 1995 created a new state structure consisting of the Federation of B\&H (FB\&H) and Republika Srpska (RS), and since 2000 the Brčko District (BD). According to the last census from 2013, B\&H has about 3.53 million inhabitants (ASB\&H, 2016), which is a significant loss in comparison with the previous census from 1991, when it had 4.37 million inhabitants. Almost 100000 people lost their lives in the 1992-1995 war and a large number fled to other countries from which some never returned. There are two dominant demographic trends which are becoming intense during the first two decades of the new millennium: negative natural increase and migration of mostly young people to developed western countries.

The process of depopulation in $\mathrm{B} \& \mathrm{H}$ is especially intense in the second decade of the 21 st century. RS has been recording a negative natural increase since 2002, and in the period 2013-2018 averaged to - 4732 annualy (RSIS, 2020). The FB\&H had a negative natural increase for the first time in 2013, while losses in the period 2013-2018 averaged to - 4580 annualy (FB\&H BS, 2020). Official estimates of entity statistics bodies say that in the period 2013-2018 RS lost 23277 and FB\&H 22 898, in total of over 46000 inhabitants. According to the FB\&H Bureau of Statistics, 24154 citizens or 4026 per year left B\&H in the same period. The total demographic losses amount to almost 13500 inhabitants per year, with a tendency of constant growth.

Agriculture plays an important socio-economic role in rural areas of $\mathrm{B} \& \mathrm{H}$; the rural population accounts for $61 \%$ and almost half of the rural households is still engaged in agriculture (Luketina et al, 2018). Statistical data indicate that the lack of a clear vision of development of agrarian and land policies in the country, lack of investments and incentives, fragmentation of the holdings as well as numerous other problems along with large deagrarization resulted in having over $50 \%$ of arable land uncultivated. The share of agricultural in the total population decreased to just $20.4 \%$ which means that every fifth or sixth person is engaged in agriculture. Trends in changes in total agricultural land by all categories of use were not linear and were considerably affected by the socio-economic development and sectoral policies (Ljuša and Čustović, 2019). Budget allocations for agricultural support in $\mathrm{B} \& \mathrm{H}$ as well as their structure are inadequate and insufficient and do not encourage farmers to invest in the production in which they would be more efficient (Makaš et al, 2018).

The biggest cause of changes in the land cover types are socio-economic processes. People change space and adapt it to their needs, spatially and temporally with stronger or weaker intensity. Where the intensity is weak or absent, natural processes dominate (overgrowing of abandoned agricultural land into shrubs/bushes, transformation of coniferous forest into mixed, etc.). Natural processes are much slower and can be observed by visualization over long periods. 
The changes that appear on the Earth's surface are visible on satellite images, and over the course of time they can be compared and thus determine the differences and directions of spatial development. Copernicus is the European Union's Earth Observation Programme. The Copernicus Land Monitoring Service (CLMS) based on data from a constellation of six families of satellites, provides geographical information on land cover and its changes, land use, vegetation state, water cycle and Earth's surface energy variables to a broad range of users in Europe. Pan-European database provides land cover and land use (LC/LU), land cover and land use changes and land cover characteristics. The CORINE Land Cover (CLC) is provided for 1990, 2000, 2006, 2012, and 2018. This vectorbased dataset includes 44 land cover and land use classes. The time-series also includes a land change layer, highlighting changes in land cover and land-use (CLMS, 2019).

The first CLC project for B\&H started in 1998 and was successfully completed in 2000. The result was the creation of the B\&H CLC 2000 database, which included the identification of the types of surface cover at the level of the main classes, and also the second and third level subclass with a detailed description of the structural characteristics. Subsequently, the CLC 2006, CLC 2012, and CLC 2018 as well as CLC Changes CHA 2000-2006, CHA 2006-2012 and CHA 2012-2018 databases were created with the aim to monitor the dynamic changes in the land cover (Drašković et al, 2020). In 2019, the European Environment Agency (EEA) published an updated illustrated guide to the nomenclature of land cover types with a structural classification at three hierarchical levels and a differentiated level of detail (details at: EEA, 2019).

The objectives of this research are to define the processes that most endanger agricultural land, to identify the subclasses of agricultural land that are most endangered as well as those subclasses that are most widespread at the expense of agricultural land.

\section{MATERIAL AND METHODS}

The basic principles of the CLC project are the visual interpretation of satellite images and as supplementary data are used: aerial images, topographic maps, statistical data, field work, etc. The basic trends of spatial development have been identified by analyzing changes in the field in the period from 2000 to 2018 in B\&H. The three most significant trends are: 1) growth of artificial surfaces, 2) growth of forests and semi-natural areas and 3) reduction of agricultural areas (Drašković, 2020). The largest changes are related to the decrease in agricultural land, which recorded a decrease of $3.65 \%$ in absolute terms in comparison with the initial year. The reasons for reduction of agricultural land are complex and mainly related to various socio-economic processes. Vector-based database on land cover types (CLC 2000, CLC 2006, CLC 2012 and CLC 2018) as well as on changes for three periods (CHA 20002006, CHA 2006-2012 and CHA 2012-2018) were used. CLC uses a Minimum Mapping Unit (MMU) of 25 hectares (ha) for areal phenomena and a minimum 
width of $100 \mathrm{~m}$ for linear phenomena. The time series are complemented by change layers, which highlight changes in land cover with an MMU of 5 ha (CLMS, 2019).

Data for the B\&H territory were extracted using GIS software and changes in the form of polygons for all three periods were visualized. The data are exported to Microsoft Excel and classified by type of change. Using the Sort \& Filter and SUBTOTAL SUM tools, individual sum of areas of all land cover types and changes that occurred by periods were calculated. By processing this data, we get a spatial and temporal insight into all the processes that take place in the field. With regard to the aim of the paper, the changes related to agricultural land have been singled out and particularly analyzed.

In general, common problems was overestimated class 2.4.3 (Land principally occupied by agriculture, with significant areas of natural vegetation), position of boundaries and a need for better separation of certain classes within agricultural areas. High resolution images from 2017/18 were extremely useful in identification of certain classes within agricultural areas that were not visible previously due to small parcel size and low resolution of images (e.g. separation of 2.2.2 in agricultural areas). In addition to this, one of the reasons for having overestimated class 2.4 .3 is that post war period was characterized by abandoned land (EEA, 2018).

\section{RESULTS AND DISCUSSION}

Based on CLC 2000, CLC 2006, CLC 2012 and CLC 2018 databases, it was established that artificial areas increased spatial coverage from $1.35 \%$ to $1.7 \%$, agricultural areas decreased from $36.81 \%$ to $33.15 \%$, forests and seminatural areas have increased from $61.08 \%$ to $64.36 \%$, while wetlands and water bodies are at about the same level (Drašković, 2020).

When it comes to subclasses of agricultural land according to the CLC 2018 database, Complex cultivation patterns (2.4.2) dominates with $43.46 \%$ (growth in comparison with 2000 of $2.58 \%$ ), Land principally occupied by agriculture, with significant areas of natural vegetation (2.4.3) with $26.11 \%$ (decrease by $4.8 \%$, explanation in the last pasus of Materials and methods), Pastures (2.3.1) with $19.09 \%$ (decrease by $2.58 \%$ ) and Non-irrigated arable land (2.1.1) with $10.39 \%$ (growth of $4.49 \%$ ) (Table 1).

A more detailed analysis of the changes including agricultural land participation shows that they cover $12 \%$ of all changes. Three types of changes in which agricultural land participates are: conversion of agricultural areas into other land cover types, conversion of other land cover types into agricultural areas and internal conversion (transition from one subclass of agricultural land to another). The largest part in the structure of changes refers to losses. The total loss of agricultural land (without internal conversion) for 18 years is $14073 \mathrm{ha}$. In the same period, the total benefit (transition of other types to agricultural land) amounted to 2768 ha. Thus, the absolute loss is 11305 ha (Table 2). 
When analyzing the changes by periods, it is noticeable that the largest net losses were recorded in the first period (2000-2006) with 9165 ha. In the next two periods, there was a significant reduction in losses to 2000 ha (2006-2012) and 2908 ha (2012-2018). The conversion of other types into agricultural land had a significantly lower intensity in all periods. In the first period, it was only 552 ha, in the second 1106 ha and in the third 1110 ha. Internal conversion was initially intensive and later gradually decreased: in the first period 4563 ha, in the second 1247 ha and in the third 425 ha. New agricultural land obtained by cultivating other types of land cover amounts to only $13.63 \%$ of the losses.

Table 3 shows that more than half of all changes or $51.51 \%$ (10 465 ha) over 18 years relate to the conversion of agricultural land into artificial surfaces, while the conversion to forests and semi-natural areas amounts to $19.52 \%$ (3 965 ha). The internal conversion within agricultural land accounts for 30.69\% (6 235 ha) and the conversion of agricultural land into water bodies $1.88 \%$ (382 ha).

Table 1: Agricultural land subclasses in B\&H for 2000 and 2018 (Level 3)

\begin{tabular}{|c|l|c|c|c|c|}
\hline & & \multicolumn{2}{|c|}{ CLC 2000 } & \multicolumn{2}{c|}{ CLC 2018 } \\
\hline Code & Land cover type & P (ha) & P (\%) & P (ha) & P (\%) \\
\hline 2.1 .1 & Non-irrigated arable land & 111161 & 5.90 & 176459 & 10.39 \\
\hline 2.1 .2 & 1.Permanently irrigated arable land & 2904 & 0.15 & 2252 & 0.13 \\
\hline 2.2 .1 & Vineyards & 1460 & 0.08 & 3021 & 0.18 \\
\hline 2.2 .2 & Fruit trees and berry plantations & 4696 & 0.25 & 7997 & 0.47 \\
\hline 2.3 .1 & Pastures & 408597 & 21.67 & 324206 & 19.09 \\
\hline 2.4 .1 & $\begin{array}{l}\text { 2.Annual crops associated with permanent } \\
\text { crops }\end{array}$ & 0 & 0.00 & 52 & 0.00 \\
\hline 2.4 .2 & Complex cultivation patterns & 773587 & 41.04 & 740732 & 43.62 \\
\hline 2.4 .3 & $\begin{array}{l}\text { Land principally occupied by agriculture, } \\
\text { with significant areas of natural vegetation }\end{array}$ & 582720 & 30.91 & 443276 & 26.11 \\
\hline & Total & 1885125 & 100.00 & 1697995 & 100.00 \\
\hline
\end{tabular}

Source: CLC database for B\&H, CLMS, 2019.

Table 2: Structure of relative changes of agricultural land by periods in (ha)

\begin{tabular}{|c|c|c|c|c|}
\hline Changes* & $2000-2006$ & $2006-2012$ & $2012-2018$ & Total \\
\hline $2 x x-x x x$ & 13728 & 3247 & 3333 & 20308 \\
\hline$x x x-2 x x$ & 5115 & 2353 & 1535 & 9003 \\
\hline $2 x x-2 x x$ & 4563 & 1247 & 425 & 6235 \\
\hline$x x x-2 x x^{*}$ & 552 & 1106 & 1110 & 2768 \\
\hline $2 x x-x x x^{*}$ & 9165 & 2000 & 2908 & 14073 \\
\hline \multicolumn{5}{|r}{ Loss } \\
\hline
\end{tabular}

* $\mathrm{x}$ can be any number from 1 to 4 and also 5 for the first column.

$* *$ Without internal conversion (without $2 \mathrm{xx}-2 \mathrm{xx}$ ). 
During the first period, $53.01 \%$ of changes accounted for the conversion of agricultural land into artificial land, $33.24 \%$ belonged to internal conversion and only $11.65 \%$ was the conversion into forests and semi-natural areas. Other conversion i.e. change of agricultural land into wetlands or water bodies accounts for $2.1 \%$. Thus, the influence of socio-economic processes during this period was dominant (internal migrations, the refugee return process etc.).

Table 3: Changes with the participation of agricultural land by periods

\begin{tabular}{|c|c|c|c|c|c|c|c|c|}
\hline & \multicolumn{2}{|c|}{ CHA 2000-2006 } & \multicolumn{2}{|c|}{ CHA 2006-2012 } & CHA 2012-2018 & \multicolumn{2}{|c|}{ Total } \\
\hline & P (ha) & P (\%) & P (ha) & P (\%) & P (ha) & P (\%) & P (ha) & P (\%) \\
\hline 2xx-1xx & 7278 & 53.01 & 1205 & 37.10 & 1982 & 59.34 & 10465 & 51.51 \\
\hline $2 x x-3 x x$ & 1600 & 11.65 & 730 & 22.48 & 905 & 27.10 & 3965 & 19.52 \\
\hline $2 x x-2 x x$ & 4563 & 33.24 & 1247 & 38.39 & 425 & 12.72 & 6235 & 30.69 \\
\hline 2xx-5xx & 288 & 2.10 & 66 & 2.03 & 28 & 0.84 & 382 & 1.88 \\
\hline Total & 13729 & 100.00 & 3248 & 100.00 & 3340 & 100.00 & 20317 & 100.00 \\
\hline
\end{tabular}

Source: CHA database for B\&H, CLMS, 2019.

Table 4: Top 10 largest changes with the participation of agricultural land by periods

\begin{tabular}{|c|c|c|c|c|c|c|c|c|c|}
\hline & \multicolumn{2}{|c|}{ CODE 2 2000-2006 } & \multicolumn{2}{c|}{ CODE 2 2006-2012 } & \multicolumn{2}{c|}{ CODE 2 2012-2018 } \\
\hline & CHA & P (ha) & P (\%) & CHA & P (ha) & P (\%) & CHA & P (ha) & P (\%) \\
\hline 1 & $242-112$ & 3655 & 26.62 & $243-222$ & 647 & 19.92 & $243-324$ & 559 & 16.74 \\
\hline 2 & $231-242$ & 2724 & 19.84 & $243-324$ & 418 & 12.87 & $231-211$ & 370 & 11.08 \\
\hline 3 & $211-112$ & 1226 & 8.93 & $242-131$ & 298 & 9.17 & $242-122$ & 337 & 10.09 \\
\hline 4 & $231-211$ & 811 & 5.91 & $231-324$ & 295 & 9.08 & $231-131$ & 305 & 9.13 \\
\hline 5 & $243-112$ & 721 & 5.25 & $243-131$ & 248 & 7.64 & $243-131$ & 258 & 7.72 \\
\hline 6 & $231-324$ & 559 & 4.07 & $242-222$ & 167 & 5.14 & $242-131$ & 246 & 7.37 \\
\hline 7 & $221-324$ & 259 & 1.89 & $211-221$ & 129 & 3.97 & $231-334$ & 166 & 4.97 \\
\hline 8 & $222-242$ & 255 & 1.86 & $242-243$ & 91 & 2.80 & $211-122$ & 134 & 4.01 \\
\hline 9 & $231-131$ & 239 & 1.74 & $211-121$ & 84 & 2.59 & $231-324$ & 133 & 3.98 \\
\hline 10 & $231-112$ & 237 & 1.73 & $242-122$ & 81 & 2.49 & $243-133$ & 113 & 3.38 \\
\hline
\end{tabular}

Source: CHA database for B\&H, CLMS, 2019.

Urbanization in developing countries in comparison with developed countries has been accelerating and this has caused by unplanned physical expansion results in more harmful undesirable effects on natural environments and the agricultural lands around and the trouble which is happening a serious treatment of urban-rural prospective (Parsipour et al, 2019). The conversion of agricultural land into artificial areas $(2 \mathrm{xx}-1 \mathrm{xx})$ is caused by the intensive human influence and urbanization, i.e. settlement construction, commercial buildings, 
infrastructure, etc. In the first period, the greatest threat to agricultural land was the expansion of suburban settlements, which accounted for about $43 \%$ of lost agricultural land. There is often a lack of quality agricultural land in the vicinity of densely populated zones, so the damage due to losses is proportionally greater.

The conversion of agricultural land to forest may be the result of natural forest expansion or tree planting (FAO, 2016). The process of leaving rural areas and overgrowing agricultural land into bushes and shrubs is taking place along with the urbanization. The conversion of agricultural land under the influence of natural processes is constantly growing. These include changes of different types of agricultural land to the Transitional woodland/shrub (3.2.4) or Natural grassland (3.2.1). This is supported by the fact that in the third period the largest change was recorded in the conversion of Land principally occupied by agriculture, with significant areas of natural vegetation (2.4.3) in the Transitional woodland/shrub (3.2.4) in the amount of 559 ha or $16.74 \%$ of all changes. Agrosocio-economic processes that take place with more or less human influence cause internal conversion. The conversion of Pastures (2.3.1) into Non-irrigated arable land (2.1.1) or Fruit trees and berry plantations (2.2.2) into the area of Complex cultivation patterns (2.4.2) is an example of such changes.

Speaking of individual changes, Table 4 shows that in the period from 2000 to 2006, the change of agricultural land into other types is most intensive in the conversion of Complex cultivation patterns (2.4.2) into a Discontinuous urban fabric (1.1.2), a total of 3655 ha or $26.62 \%$ of all changes. The zones with the largest spread of discontinuous urban area due to complex cultivation were recorded in the vicinity of Sarajevo (195 ha and 106 ha), Tuzla (168 ha, 165 ha and $100 \mathrm{ha}$ ) (Figures 1 and 2) and Zvornik (111 ha).
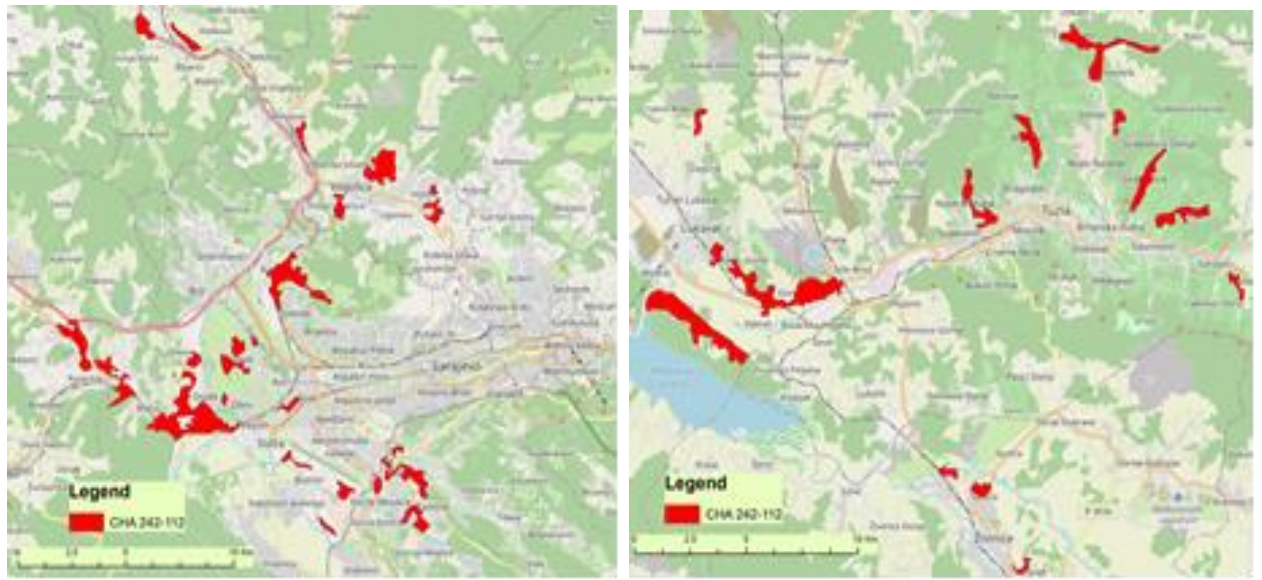

Figure 1 and 2: Spreading of discontinuous urban areas (1.1.2) to areas covered by complex cultivation (2.4.2) near the cities of Sarajevo and Tuzla

The next biggest change in that period refers to the internal conversion within agricultural land, i.e. Pastures (2.3.1) were transferred to Complex 
cultivation patterns (2.4.2) in the amount of 2724 ha or $19.84 \%$. This does not represent a loss since one type of agricultural land has been qualitatively replaced by another. Furthermore, there is a significant loss of Non-irrigated arable land (2.1.1) in the Discontinuous urban fabric (1.1.2) in the amount of 1226 ha or $8.93 \%$ of changes. The next largest change relates to the internal conversion of Pastures (2.3.1) into Non-irrigated arable land (2.1.1) in the amount of 811 ha or $5.91 \%$. Land principally occupied by agriculture, with significant areas of natural vegetation (2.4.3) are also transferred to a Discontinuous urban fabric (1.1.2) in the amount of 721 ha or $5.25 \%$. Among other external changes, mention should be made of the conversion of Pastures (2.3.1) and Vineyards (2.2.1) into the Transition woodland/shrubs (3.2.4) and Pastures (2.3.1) into a Discontinuous urban fabric (1.1.2).

Changes during the second and third period were less intense (Figure 3). The spread of discontinuous urban area over agricultural land has almost disappeared. The reasons are to be found in the mainly completed refugee return process, the 2008 global economic crisis and negative demographic trends.

During the second period (2006-2012), internal conversion was the most dominant process with $38.39 \%$ of the total changes involving agricultural land. The largest change was recorded in the conversion of Land principally occupied by agriculture, with significant areas of natural vegetation (2.4.3) into Fruit trees and berry plantations (2.2.2) in the amount of 647 ha or $19.92 \%$ of changes. Internal conversion is among the top 10 biggest changes represented by the conversion of Complex cultivation patterns (2.4.2) into Fruit trees and berry plantations (2.2.2), Non-irrigated arable land (2.1.1) into Vineyards (2.2.1) and Complex cultivation patterns (2.4.2) in Land principally occupied by agriculture, with significant areas of natural vegetation (2.4.3). The largest losses of agricultural land were related to the conversion of Land principally occupied by agriculture, with significant areas of natural vegetation (2.4.3) and Pastures (2.3.1) into the Transition woodland/shrubs (3.2.4). The conversion of agricultural land into forests and semi-natural areas has doubled in comparison with the previous period to $22.48 \%$. Natural processes without human activities become more intense. Conversion to water bodies accounts for $2.03 \%$. Concerning artificial areas, agricultural land was most endangered by Mineral extraction sites (1.3.1) built in areas with Complex cultivation patterns (2.4.2) and Land principally occupied by agriculture, with significant areas of natural vegetation (2.4.3) in the amount of 298 ha and 248 ha.

Anyway, the pattern of agricultural development in $\mathrm{B} \& \mathrm{H}$ is quite different comparing with previous period. In particular, consumption of pastures, the most significant trend in previous period, ended up. The main reason for this decrease of pasture consumption intensity is the significant slowdown of urban residential sprawl and of internal agricultural conversion from pasture to arable land and permanent crops, as these flows were the main consumers of pasture land in the previous period (EEA, 2017). 
During the third period (2012-2018), the dominant process is again the expansion of artificial areas at the expense of agricultural land in the amount of 59.34 percent of all changes. Natural processes of conversion of agricultural land into forests and semi-natural areas continue to grow continuously with a share of $27.1 \%$ of all changes. Internal conversion within agricultural land decreased to only $12.72 \%$. The remaining conversion is $0.84 \%$ (Table 3 ).

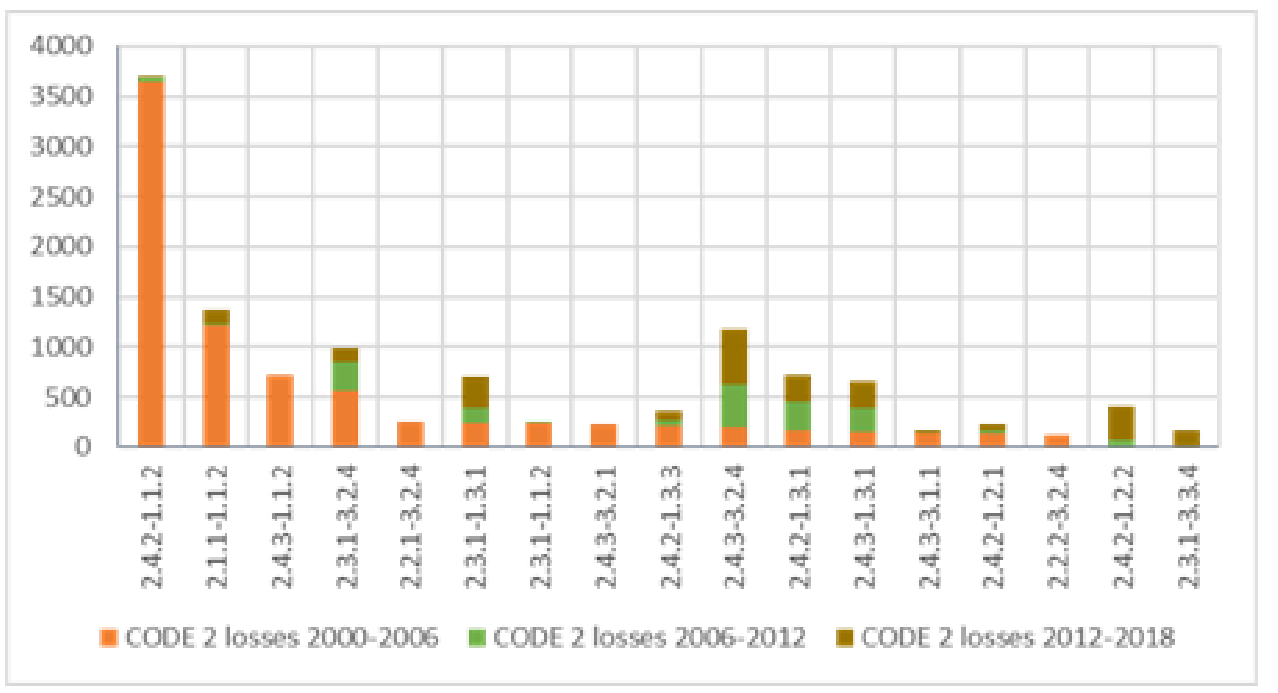

Figure 3: Structure of the agricultural land losses by periods

The largest change was recorded in the conversion of Land principally occupied by agriculture, with significant areas of natural vegetation (2.4.3) in the Transition woodland/shrubs (3.2.4) with 599 ha. Mineral extraction sites (1.3.1) occupied the former areas under Pastures (2.3.1) with 305 ha, Land principally occupied by agriculture, with significant areas of natural vegetation (2.4.3) with 258 ha and Complex cultivation patterns (2.4.2) with 246 ha. In addition, Complex cultivation patterns (2.4.2) and Non-irrigated arable land (2.1.1) were replaced with Road and railway network and associated land (1.2.2) in the amount of 337 ha and 134 ha (mainly related to the construction of the highway Banja Luka - Doboj). It is important to mention the losses of Pastures (2.3.1) in the Burnt areas (3.3.4) with 166 ha and the Transition woodland/shrubs (3.2.4) with 133 ha. Higher internal conversion was recorded by changing Pastures (2.3.1) into Non-irrigated arable land (2.1.1) to 370 ha.

\section{CONCLUSIONS}

The analysis of the structure of changes with agricultural land participation in $\mathrm{B} \& \mathrm{H}$ shows that the largest changes were recorded during the first period (2000-2006). In that period, there was the largest decrease of agricultural and, mainly owing to the expansion of discontinuous urban areas in the amount of $43 \%$ of total changes. In the second period (2006-2012), the external conversion 
of agricultural land into other types of cover in absolute terms was significantly reduced. The expansion of urban zones over agricultural land was minimal, but the construction of mines and construction sites on agricultural land was intensified. The conversion caused by natural processes has doubled. The largest losses were recorded by the expansion of the transitonal woodland/shrub area. In the third period (2012-2018), the conversion of agricultural land into artificial land increased to a record $59.34 \%$. The road and railway network, as well as mines and constuction sites, were mainly expanded at the expense of agricultural land. At the same time, there was a further increase in the conversion of agricultural land into forest and semi-natural areas, of which most land principally occupied by agriculture, with significant areas of natural vegetation and pastures into the transitional woodland/shrub. Part of the area under pastures was affected by fires and converted into a burned zone.

Two parallel processes are dominant: urbanization and deagrarization. The population is concentrated around larger cities while rural areas are sparsely populated. The biggest losses of agricultural land occur owing to the expansion of artificial areas. However, as demographic losses increase over time, natural processes become more intense in an increasing area. Former agricultural lands become uncultivated and over time grow into shrubs and bushes.

\section{REFERENCES}

Agency for statistic of Bosnia and Herzegovina (ASB\&H) (2016): Census of Population, Households and Dwellings in Bosnia and Herzegovina, 2013. Sarajevo. Statistical Database. Available at: http://www.statistika.ba/ (accessed November 15, 2020)

Copernicus Land Monitoring Services (CLMS) (2019): CORINE Land Cover. Database.

Available at: http://land.copernicus.eu/pan-european/corine-land-cover/ (accessed February 02, 2019)

Drašković B., Ponosov A., Zhernakova N., Gutalj M. \& Miletić B. (2020). Land cover types and changes in land use in Republic of Srpska (Bosnia and Herzegovina) over the period 2000-2018. Journal of the Geographical Institute "Jovan Cvijic'" SASA, 70 (1), pp 81-88.

Drašković B. (2020): Trends of spatial development in Bosnia and Herzegovina, Journal "Geographical review", 42, pp 57-67, Geographical society in Federation of Bosnia and Herzegovina, Sarajevo, Faculty of Science.

European Environment Agency (EEA) (2019): Corine Land Cover Nomenclature

Guidelines. Available at: https://land.copernicus.eu/user-corner/technicallibrary/corine-land-cover-nomenclature-guidelines $/ \mathrm{html}$

European Environment Agency (EEA) (2018): CLC 2018 B\&H Final Report Information Available at:

http://cdr.eionet.europa.eu/ba/eea/clc/envw6skew/CLC2018_BA_Final_Report_In formation.pdf

European Environment Agency (EEA) (2017): Bosnia and Herzegovina land cover country fact sheet 2012. Available at:

https://www.eea.europa.eu/themes/landuse/land-cover-country-fact-sheets/babosnia-and-herzegovina-landcover-2012.pdf/view 
FAO (2016): State of World's forests, Forest and Agriculture, Land-use: Challenges and opportunities. Available at: http://www.fao.org/3/a-i5588e.pdf (accessed Decambar 25, 2020)

FB\&H Bureau of Statistics (FB\&H BS) (2020): Thematic bulletins - population and register, Sarajevo. Available at: http://fzs.ba/index.php/publikacije/godisnjibilteni/stanovnistvo-i-registar/ Statistical Database. (accessed November 18, 2020)

Luketina, R., Bilali el, H., Berjan, S., Wurzinger, M. (2018): Sustainability transitions in Bosnian agro-food system. Agriculture and Forestry, 64 (4): 29-38. DOI:10.17707/AgricultForest.64.4.04

LJuša, M. \& Čustović, H. (2019): Agricultural land use and land losses in Bosnia and Herzegovina in period 1961-2018. Agriculture and Forestry, 65 (1): 147-156. DOI:10.17707/AgricultForest.65.1.15

Makaš, M., Bajramović, S., Erjavec, E., Rednak, M. (2018): Assessment of overall support to agriculture in Bosnia and Herzegovina. Agriculture and Forestry, 64 (4): 165-172. DOI:10.17707/AgricultForest.64.4.18

Parsipour, H., Popovic, S., Behzadfar, M., Skataric, G., Spalevic, V. (2019): Cities expansion and land use changes of agricultural and garden lands in peri-urban villages (case study: Bojnurd). Agriculture and Forestry, 65(3): 173-187

Republika Srpska Institute of Statistics (RSIS) (2020): Statistical Yearbook, Demographic statistics. Banja Luka. Available at:

https://www.rzs.rs.ba/static/uploads/bilteni/stanovnistvo/BiltenDemografskaStatist ika_2020_WEB.pdf Statistical Database (accessed November 18, 2020) 